\title{
PERSPECTIVA POÉTICA DE NEGOCIAÇÃO — PROPOSTA TEÓRICA E METODOLÓGICA PARA DISCUTIR O PROCESSO DE ADAPTAÇÃO FÍLMICA DE ROMANCES
}

\author{
Juliana de Fátima Alves da Silva ${ }^{1}$ \\ José Francisco Serafim²
}

\begin{abstract}
Resumo: Este artigo discute questões relativas à adaptação de obras literárias para o cinema, buscando desenvolver e apresentar uma proposta metodológica e teórica que possibilite orientar a discussão sobre o assunto em uma direção mais apropriada do que tem percorrido os estudos recentes sobre o tema. Denominamos tal proposta de Perspectiva Poética de Negociação. $O$ desenvolvimento desta proposta está diretamente relacionado à maneira como se define o processo de adaptação. Nesse sentido, neste trabalho, sugerimos como a adaptação deve ser entendida conceitualmente e, posteriormente, se apresenta os elementos e parâmetros metodológicos que permitem ao analista tanto verificar como cada obra (filme e romance) está configurada narrativamente para provocar determinados efeitos, assim como compará-las, observando o que foi transferido e o que foi transformado de uma para outra.

Palavras-Chave: Adaptação; Cinema; Narratologia; Poética.
\end{abstract}

Abstract: This article discuss about the adaptation of literary works into film, to develop and present a theoretical and methodological proposal that allows the discussion on the subject in a appropriate direction that has driven the recent studies on this subject. We call such proposal as Poetic Perspective of Negotiation. The development of this proposal is related to how we define the adaptation process. In this work, we suggest that the adaptation must be understood conceptually and then it presents the methodological elements and parameters that allow the analyst to see how each work (film and novel) is set to cause effects in a narrative, like comparing them, observing what was transferred and what has been transformed from one to another.

Key Words: Adaptation; Cinema; Narratology; Poetic.

1 Mestre em Comunicação pelo Programa de Pós-Graduação em Comunicação e Cultura Contemporânea da Universidade Federal da Bahia (UFBA); Membro do Grupo de Pesquisa de Análise Fílmica. Endereço eletrônico: jufasilva@gmail.com.

2 Doutor em Cinema pela Universidade Paris X - Nanterre; Professor Adjunto da Faculdade de Comunicação da UFBA; Pesquisador do Programa de Pós-Graduação em Comunicação e Cultura Contemporânea da UFBA; Coordenador do Grupo de Pesquisa em Análise Fílmica. Endereço eletrônico: josefserafim@ufba.br. 


\section{CONTEXTUALIZAÇÃo GERAL}

Os inúmeros exemplos de adaptações de obras literárias e os diversos fatores favoráveis à realização delas - como a propensão comum entre cinema e literatura se desenvolverem narrativamente, o aprimoramento da linguagem narrativa cinematográfica, o sucesso econômico de determinadas adaptações, o interesse do público por temas e títulos de obras literárias consagradas - revelam claramente a existência de uma relação anti$\mathrm{ga}^{3}$, produtiva e ininterrupta entre a manifestação artística literária e a cinematográfica. Paralelo a este terreno propício à produção prática de transposições fílmicas de obras literárias, é natural que tenha surgido também um território favorável à realização de estudos a respeito da questão. As discussões ao redor do assunto da adaptação cinematográfica têm suscitado uma diversificada, opositiva e extensa produção bibliográfica, apresentada em pequenos ou longos textos de caráter "teórico" ou meramente opinativo.

As primeiras discussões na área dos estudos de comunicação/cinema surgem e se desenvolvem de uma maneira essencialmente comparatista e conflitiva. Ora aproxima-se, ora diferencia-se a arte cinematográfica da literária, a fim de, sobretudo, se legitimar e se delimitar as características específicas do cinema. Exemplos disto são os estudos iniciais sobre a arte cinematográfica, realizados por Jean Epstein, Béla Balázs, André Bazin, Sergei Eisenstein, Siegfried Kracauer e os vanguardistas europeus (Ricciotto Canuto, Jean Epstein, Abel Gance e Louis Delluc). Já os estudiosos interessados na arte literária evitam, pelo menos inicialmente, reconhecer qualquer benefício na relação entre o filme e o romance. Preferem, por sua vez, basear-se em noções de primazia da arte literária sobre a cinematográfica, autoria e respeitabilidade. Posteriormente, apoiam a prática da adaptação, defendendo principalmente a fidelidade do filme ao romance, como é o caso, por exemplo, de Virginia Woolf e de Claude Gauteur. Além de valorizarem também a relação de interdependência entre cinema e literatura e a noção de recriação, como Boris Eichenbaum, Georges-Albert Astre, Philippe

3 Adaptações cinematográficas de obras literárias realizam-se praticamente desde o surgimento do cinema, fim do século XIX e início do século XX. O comum potencial para contar estórias é um dos principais motivos para que o encontro entre as duas artes tenha se efetivado desde tão cedo e que se tornasse uma prática inevitável e frequente até hoje (MCFARLANE, 1996; PEÑA-ARDID, 1992; BORDWELL, 1985; VANOYE, 1994; JOST, 1995; NAREMORE, 2000; VERNET 2002; e RAY, 2000).

144 Número temático: literatura e cinema. A Cor das Letras - UEFS, n. 11, 2010 
Durand, etc. Há ainda exemplos de escritores que aderem até mesmo à atividade prática de adaptações, realizando roteiros cinematográficos: William Faulkner, John Dos Passos e Scott Fitzgerald (PEÑA-ARDID, 1992; BRITO, 1995).

O resultado é, então, uma série de trabalhos permeados por noções de liberdade criativa e recriação e por oposições binárias: alta cultura versus cultura de massa, original versus cópia. Desse modo, segundo Dudley Andrew (2000), a mais comum e frequente discussão sobre adaptação vem girando em torno de duas posições opostas, Fidelidade ou Recriação.

\section{FIDELIDADE E RECRIAÇÃO — EM TERMOS CONCEITUAIS E METODOLÓGICOS}

Apesar dessas duas abordagens, que denominamos Perspectiva Poética de Fidelidade e Perspectiva Poética de Recriação, se desenvolverem concomitantemente, com relativa independência de sua situação na diacronia, as concepções da Perspectiva de Fidelidade têm predominado na maioria dos estudos sobre adaptação, sobretudo naqueles produzidos entre anos de 1920 a 1960. Em termos conceituais, as concepções que delineiam o quadro de discussão da Perspectiva Poética de Fidelidade enfatizam a ideia de traição ao original, do desnível qualitativo entre o filme e o romance, da superioridade da arte literária em relação ao cinema, da necessidade de respeitabilidade à obra-fonte, da especificidade de cada arte, da existência de um sentido principal e único da obra, etc. Já, em termos metodológicos, propõe, de um modo geral, que a análise de adaptação deve privilegiar em primeiro plano a compreensão da obra literária, a fim de mostrar, sobretudo, aquilo que a diferencia ou que lhe faz "melhor" do que a obra fílmica (BALOGH, 1996).

É apenas por volta da década 1980 em diante que esse quadro tende a adquirir uma nova configuração. Passa-se a relativizar a noção de fidelidade, salientando-se a interferência promovida pelo adaptador e a transformação como práticas inerentes ao processo de adaptação. Essas concepções levam as pesquisas a se voltarem para o estudo de adaptações com base na noção de recriação. Atualmente, a Perspectiva da Recriação tem permeado a maioria dos estudos sobre adaptação. Exemplos contemporâneos são as pesquisas de Patrick Cattrysse (1992), Ana Maria Balogh (1996), Dudley Andrew (2000), Ismelda Whelehan (1999), James Naremore (2000), Marinyze Prates de Oliveira (2004), Randal Johnson (2003), Robert Stam (2000; 2008) e Robert Ray (2000), entre outros.

Cláudio Cledson Novaes, Fernanda Aguiar C. Martins, Roberto H. Seidel (Org.) 
Em termos conceituais a Perspectiva Poética de Recriação parte do pressuposto básico de que a Perspectiva Poética de Fidelidade teria se desenvolvido com argumentos "teóricos" (conceituais) e propostas metodológicas pouco ou mal elaborados,

[...] nenhum método tem sido desenvolvido até hoje que nos permitiria a estudar a adaptação fílmica em um caminho sistemático [...] as abordagens [...] não fornecem instrumentos analíticos para estudar e comparar textos do filme. Além disso, alguns de seus conceitos teóricos (por exemplo, normas, modelos, sistemas, domínios) estão necessitando de mais elaboração (CATTRYSSE, 1992, p. 54; 60-61) ${ }^{4}$.

Assim, procuram criticar, opor-se e até mesmo desvalidar os trabaIhos da Perspectiva Poética de Fidelidade, usando noções de interdependência e as possibilidades de interação entre as artes, as diferenças expressivas entre as artes, a liberdade de criação, o estilo individual, a intertextualidade, a interpretação livre e múltipla e a transformação de uma obra ao ser traduzida para outra linguagem. Dessa maneira, acreditamos que a Perspectiva de Recriação tanto pretende enfraquecer e desvalidar as concepções da Perspectiva de Fidelidade quanto sugerir explícita e implicitamente que seus conceitos e métodos são "modelos" mais aprimorados, coerentes e convincentes.

Por sua vez em termos metodológicos, os adeptos da Recriação defendem que o filme - baseado ou não em obra literária - seja analisado antes de tudo como um filme e não como adaptação (JOHNSON, 1982). Nesse sentido, a abordagem metodológica da recriação propõe que o texto final (filme) seja analisado independente do texto-base (romance). Sugerese também que fatores contextuais sejam levados em consideração.

Embora reconheçamos a importância dos trabalhos da Perspectiva de Recriação para o avanço do campo de estudos "Cinema e Literatura" e embora atualmente essa proposta seja unanimemente aceita e defendida sendo incomum encontrarmos outros tipos de perspectivas e estudos que a critiquem -, ao a analisarmos mais profundamente, percebemos que apresenta controvérsias e não está em um patamar "teórico" e metodológico "superior" (ou "melhor") do que o da Perspectiva de Fidelidade, como sugere.

Assim, é fundamental que repensemos como o estudo do tema tem se dado. Mas, mais do que apenas repensar, precisamos desenvolver, propor e aprimorar noções teóricas e metodológicas para discutir o assunto da

4 Tradução nossa.

146 Número temático: literatura e cinema. A Cor das Letras - UEFS, n. 11, 2010 
adaptação fílmica de uma maneira mais equilibrada do que o tem sido feito. Nessa perspectiva, este artigo sugere uma proposta conceitual e metodológica para se tratar o assunto da adaptação. Intitulamo-la de Perspectiva Poética de Negociação. Esta é uma denominação nova, sugerida neste trabalho, para referir-se ao entendimento conceitual e metodológico do processo de adaptação como uma Poética de Negociação de "manutenção" e/ou "transformação" de elementos e aspectos narrativos e recursos poéticos. Todavia, antes de apresentar propriamente as noções da Perspectiva de Negociação, vamos discutir brevemente quais as principais controvérsias existentes nos estudos da Perspectiva de Recriação e da de Fidelidade.

\section{CONTROVÉRSIAS COM AS NOÇõES DE RECRIAÇÃO}

Os adeptos da recriação, entre outras coisas, utilizam noções de intertextualidade, de "obra aberta" e de "interpretação", para defender que cada adaptação seja analisada como uma experiência individual de leitura e de interpretação. Dessa forma, afirmam que o texto literário seria uma estrutura aberta para ser atualizada (interpretada) de distintas maneiras pelo leitor. Nesse sentido, Robert Stam (2000, p. 57) afirma:

O texto literário não é fechado, mas uma estrutura aberta [...] para ser retrabalhada em um contexto ilimitado. $O$ texto alimenta e é alimentado por infinitos intertextos permutáveis, os quais são vistos através de grades mutáveis de interpretações 5 .

Ao sugerirem que o texto literário seria uma estrutura aberta, apropriam-se implicitamente dos conceitos de "poética da obra aberta" e de "interpretação ilimitada", sugeridos por Umberto Eco nas seguintes obras: Lector in fabula (1986), Obra aberta: forma e indeterminação nas poéticas contemporâneas (1971) e Os limites da interpretação (1995).

Utilizam-se da noção de "obra aberta" e de "interpretação ilimitada", na medida em que consideram que a obra de arte seria um objeto (texto) organizado com uma estrutura "aberta" (indefinida ou indeterminada), ou seja, com uma série de sinais, a fim de solicitar a cooperação do intérprete, de forma que ele viesse sentir-se estimulado a frequentar o percurso de sentido que quisesse. Assim, as interpretações gozariam de uma liberdade de execução, de modo que cada uma seria a cada vez uma nova criação.

5 Tradução nossa.

Cláudio Cledson Novaes, Fernanda Aguiar C. Martins, Roberto H. Seidel (Org.) 
Ao propor que a interpretação seria uma prática de leitura livre e subjetiva, os adeptos da recriação nos levam a crer que seria impossível definirmos e determinarmos um tipo de interpretação único e correto, considerando, portanto, que toda e qualquer leitura de um texto poderia ser considerada propriamente uma interpretação. Além de sugerirem que, sendo a adaptação fílmica de obras literárias resultante de uma leitura inevitavelmente pessoal e livre, toda e qualquer leitura de uma obra literária feita por um cineasta seria uma interpretação "válida" e, portanto, uma adaptação propriamente dita. Nesse sentido, podemos dizer que para os adeptos da recriação, a adaptação estaria sujeita tanto a resultar em práticas de leituras que correspondem ao mesmo sentido textual da obra literária quanto a originar leituras radicais, que desfiguram a obra literária "ao ponto de lhe demolirem a arquitetura textual, através de decisões interpretativas narrativamente infelizes e equiparáveis ao princípio de que tudo pode" (SOUSA, 2001, p. 2).

O problema com essas concepções "teóricas" da Perspectiva de Recriação é que desconsideram a diferença entre interpretar e usar uma obra - tratando a noção de interpretação, defendida por Umberto Eco (1971), não como pré-condição para haver liberdade de leitura e criação, porém como pré-condição para uso deliberado ou como um convite amorfo ao uso indiscriminado - e desvirtuam o conceito de adaptação propriamente dito.

Contudo, analisando com mais rigor os conceitos da "poética da obra aberta", sugeridos por Eco, percebemos que indeterminação, infinitude, multiplicidade, subjetividade e liberdade de interpretação não implicam em arbitrariedade, como propõe a Perspectiva de Recriação. Isso porque, para Eco, a própria obra rege os caminhos de sua interpretação. Assim, deve ser vista como um objeto produzido por um autor, que organiza previamente uma série de estratégias, de modo que cada possível fruidor possa recompreender a mencionada obra, a forma originária imaginada por ele. Então, a ideia de arbitrariedade perde força, pois passamos a entender que a interpretação deve ser submetida à intenção do texto (intento operis) e não à intenção do leitor (intento lectoris) ou do autor (intento auctoris) (GOMES, 2004b).

Não queremos dizer que a arbitrariedade e a subjetividade do intérprete devem ser tolhidas ou que é fácil definir diante da atividade interpretativa o que é válido ou qual é a melhor interpretação do texto. A noção de que a atividade de interpretar é sempre o movimento de um sujeito, uma atividade pessoal e livre, um agir que penetra subjetivamente em uma con- 
quista própria, original, nova, proposta pela "poética da obra aberta" e defendida pela perspectiva de recriação, continua a ser aceita, só que sem implicar em arbitrariedade ou uso deliberado da obra, e consequentemente, na afirmação de que toda e qualquer leitura de um texto deve ser vista como uma interpretação e uma adaptação propriamente ditas, como faz a Perspectiva de Recriação.

\section{APONTAMENTOS PARA ALÉM DA FIDELIDADE E/OU RECRIAÇÃo}

Os estudos em torno do tema adaptação precisam superar o extremismo e as controvérsias metodológicas e conceituais presentes na Perspectiva Poética de Fidelidade e na de Recriação. Em termos conceituais, embora concordemos com a afirmação da Perspectiva de Recriação, que defende que a adaptação cinematográfica é um processo de recriação pois, primeiro, o cineasta desarticula o discurso original e, depois, reconfigura as informações que tem em um novo discurso - , não podemos partir para o extremo oposto, que propõe tal Perspectiva, de considerar toda e qualquer leitura uma adaptação e desconsiderar questões de fidelidade na análise de adaptações.

Já em termos metodológicos, deve-se sair do extremismo de supervalorizar a análise do romance sobre o filme e de dar prioridade à análise dos aspectos diferenciais entre ambos, como faz a Perspectiva Metodológica de Fidelidade, ou do extremismo de priorizar a análise do filme sobre a do romance e de dar ênfase à verificação das diferenças entre o meio fílmico e o literário, como faz a Perspectiva de Recriação.

Com base em tudo o que foi dito, apresentamos e desenvolvemos, resumidamente, no restante deste artigo, uma proposta "conceitual" e "metodológica", intitulada Perspectiva Poética de Negociação.

\section{Perspectiva poÉtica de negociação}

A Perspectiva Poética de Negociação é uma proposta que fornece bases conceituais e metodológicas para discutir e orientar a análise das adaptações fílmicas de obras literárias. Apesar da carência de trabalhos que debatam a questão do mesmo modo como discutimos, pesquisadores como Brian McFarlane (1996), Mieke Bal (1995), Sérgio Sousa (2001) e Umberto Eco (2007) contribuem para o desenvolvimento da proposta conceitual, que 
defendemos. Já a metodologia da Perspectiva Poética de Negociação é configurada com base na aplicação de outras duas metodologias: a) Poética do Filme $^{6}$ (GOMES, 1996; 2002; 2004a; e b) Narratologia (BAL, 1995) ${ }^{7}$. Utilizamos também de conceitos de Narratologia de outros pesquisadores, como Gérad Genette (1972), François Jost (1995), David Bordwell (1985), Carmen Peña-Ardid (1992), Francis Vanoye (1994), Jacques Aumont (2002) e Michel Marie (1990).

\section{PoÉtICA DE NEGOCIAÇÃo - EM TERMOS CONCEITUAIS}

O desenvolvimento da proposta conceitual e metodológica da Perspectiva Poética de Negociação está diretamente relacionado à maneira como definimos e compreendemos o processo de adaptação de obras literárias para o cinema. Entendemos, que adaptação é um processo recriativoindicial que, longe de equivaler a uma apreensão integral do significado de uma obra - operação já por si impossível -, impregna e revela os traços de uma atividade de tradução que por um lado guarda sempre algum vínculo formal, temático, semântico-narrativo ou discursivo com a obra que the deu origem - mesmo quando lhe subverte o sentido - e, por outro, corresponde a uma construção regida por princípios muito próprios, que devem conferir-lhe autonomia em relação ao texto-base e sustentá-la enquanto obra fílmica. Em outras palavras, é um processo que resulta na constituição de uma nova obra (filme) através tanto da interpretação individual do cineasta, do manuseio de técnicas cinematográficas específicas e

6 A metodologia Poética do Filme é desenvolvida pelo grupo de Pesquisa de Análise Fílmica do Programa de Pós-Graduação em Comunicação e Cultura Contemporânea (UFBA), coordenado pelo Professor Doutor José Francisco Serafim e Pós-Doutor Wilson Gomes. Trabalhos de pesquisadores deste Grupo de Pesquisa que tem contribuído para o desenvolvimento e aprimoramento da metodologia: Poética do filme: a poética dos anjos caídos: um estudo sobre o cinema de Wong Kar-Wai (2004), A fabricação do ídolo pop: a análise textual de videoclipes e a construção da imagem de Madonna (2005), Coração de ouro: o cinema melodramático de Lars Von Trier (2006), Elementos para uma poética da música do cinema: ferramentas conceituais e metodológicas aplicadas na análise da música dos filmes "Ajuste final" e "O homem que não estava lá" (2007), A construção narrativa e plástica do filme Matrix (2008), entre outros.

Detemo-nos a Bal, por este propor uma síntese das muitas perspectivas de abordagem da questão da narrativa, apresentando, por fim, uma narratologia coerente, sistemática e concisa, e sobretudo "manuseável" por todo aquele que se proponha a analisar os processos de significação em textos diversos, sejam literários, cinematográficos, etc.

150 Número temático: literatura e cinema. A Cor das Letras - UEFS, n. 11, 2010 
da rearticulação das estruturas semântico-narrativas e discursivas do texto literário, quanto da manutenção de determinados aspectos dessa estrutura, que permita a remitência (indicial, referencial) à estrutura do universo do texto-fonte. A adaptação é, portanto, um processo sério, que impõe uma deontologia profissional que nenhuma teoria desconstrutivista pode neutralizar.

Embora a adaptação fílmica de romances não possa restituir nem tornar reversível na passagem romance-filme todos os valores semânticos e discursivos ou todas as engrenagens e artimanhas de produção de efeitos, presentes na obra de partida, ela pode pelo menos tentar ou até mesmo dizer "quase a mesma coisa" ${ }^{8}$ (mesmo que de outro modo). É, então, em torno da capacidade de perceber como a adaptação opera, relacionando, colocando em equivalência e readequando os programas de produção efeito do texto fílmico e literário, que deve se basear o trabalho dos interessados pelo assunto. O que permite a percepção de como isso ocorre é o fato de tanto a poética da obra literária quanto a da obra cinematográfica terem como elemento conjuntivo a narratividade.

Diante desse entendimento de adaptação, definimos que adaptação fílmica é um processo poético de negociação que opera através de conjunções e disjunções - entre elementos e recursos narrativos e modos de manipulação desses - de dois sistemas com materiais significantes distintos. A observação deste esquema de negociação - o que pode ser mantido do texto narrativo e o que pode sofrer alterações - é fundamental para discutir todo e qualquer processo de adaptação literatura-cinema.

Para Brian McFarlane (1996), o que pode ser transferido, porque não está comprometido nem com um nem com outro sistema, é, essencialmente, a fábula; e o que requer processos intrínsecos de "adaptação", porque seus efeitos estão comprometidos aos sistemas semióticos em que eles estão manifestados, é a trama. Assim, a identificação desses níveis é fundamental para darmos início à análise de adaptações.

8 Umberto Eco (2007) explica que traduzir é dizer "quase a mesma coisa" em outra língua. Ou seja, partindo do pressuposto que uma tradução não pode nunca dizer a mesma coisa, o autor procura compreender então como se pode dizer quase a mesma coisa.

Cláudio Cledson Novaes, Fernanda Aguiar C. Martins, Roberto H. Seidel (Org.) 


\section{TRAMA E FÁBULA NO PROCESSO DE ADAPTAÇÃO}

A fábula diz respeito ao "sobre-o-que-se-fala" na obra. Em outras palavras, refere-se a certa história contada, a certos personagens, a uma sequência de acontecimentos que se sucedem num determinado lugar (ou lugares), num determinado intervalo de tempo (BAL, 1995). Por não depender de um meio específico para ser contada e por ser composta de elementos que se referem às ações e aos acontecimentos narrativos, como o nome dos personagens, caracterização visual, a ordem em que os eventos aparecem na trama, a presença de alguns cenários, a fábula pode muito bem ser transferida do meio literário para o cinematográfico, sem necessariamente precisar sofrer alterações.

Já a trama ${ }^{9}$ corresponde ao modo como esta fábula chega ao conhecimento do leitor, ou seja, ao modo como ela é contada. É nesse nível, que se operam as intervenções, as manipulações dos elementos narrativos e as estratégias de produção de efeitos. Assim, é no nível da trama que ocorrem as transformações e "adaptações" quando realizadas adaptações fílmicas de obras literárias - como, por exemplo, muito do que é levado às telas pode ser perfeitamente inferido do texto verbal, como os sentimentos dos personagens, mas necessitam obviamente de "adaptação" - ou seja, não podem ser transportados em forma de texto, por assim dizer, óbvia e diretamente, ao cinema. Desse modo, é no estudo e análise desse nível que podemos perceber mais claramente como a narrativa literária é transmutada na narrativa cinematográfica.

\section{POÉTICA DE NEGOCIAÇÃO — EM TERMOS METODOLÓGICOS}

A Perspectiva Poética, em termos metodológicos, tem como base conceitual que adaptação é um processo de negociação entre os elementos, aspectos, estratégias e recursos narrativos que são transferidos ou mantidos e os que são inevitavelmente transformados para configurar determinados efeitos de uma obra para outra. Assim, fornece os elementos e

9 Bal não utiliza propriamente o termo trama, mas sim texto e história. Contudo, vista a complementaridade de seus conceitos, correspondendo, ambos, a atividade do tramar, do manipular artisticamente a fábula, os tratamos como parte de um mesmo estrato, denominado de trama.

152 Número temático: literatura e cinema. A Cor das Letras - UEFS, n. 11, 2010 
parâmetros metodológicos que permitem ao analista tanto verificar como cada obra (filme e romance) está configurada narrativamente para provocar determinados efeitos, assim como compará-las, observando o que foi transferido e o que foi transformado de uma para outra.

Metodologicamente, sugerimos, então, que em um primeiro momento 1) se deve estudar os romances e os filmes separadamente, observando os elementos e aspectos estruturais que compõem a narrativa, tanto no nível da fábula quanto da trama. Depois 2), se examina como eles funcionam no intento de narrar, de contar uma história, gerando determinados efeitos em um leitor-modelo. E por fim, 3) se analisa como tais elementos, aspectos e recursos, que operam em cada nível narrativo (trama e fábula) das obras (filme e romance), se equiparam, de modo a que se aufira de tal exercício comparativo a identificação das negociações das continuidades e descontinuidades que intermediam a relação do filme com a sua obra literária de origem. Nesse sentido, tal metodologia sugere que o processo de adaptação deve ser analisado imanente e comparativamente. Daí ser necessário se utilizar da Narratologia e da Poética do Filme ${ }^{10}$.

Além da Narratologia e da Poética do Filme, a Perspectiva de Negociação considera também aspectos contextuais, como ideologia, período histórico, local de produção, fatores socioculturais, políticos e econômicos, uma vez que permitem compreender determinadas escolhas e configurações de sentido efetuadas na realização de adaptações.

\section{NARRATOLOGIA E ADAPTAÇÃO CINEMATOGRÁFICA}

Nos estratos da trama e da fábula existem vários componentes que devem ser verificados na análise do processo de adaptação. Mieke Bal (1995) denomina "elementos" os componentes da fábula, e "aspectos", os da trama. Explicitamos, resumidamente, alguns dos componentes, apenas como forma de mostrar os recursos que devem ser levados em consideração nas análises das narrativas tanto fílmicas quanto literárias, sempre observando as especificidades de cada meio. Não discutimos profundamente

10 Embora a Poética do Filme tenha sido criada para contemplar a análise de filmes, a análise das obras literárias, que originam adaptações cinematográficas, pode também ser conduzida segundo as mesmas regras aplicadas ao estudo dos filmes, pois, conforme Gomes (2004b, p. 105), "a rigor, pode-se trabalhar analiticamente com qualquer material expressivo usando basicamente os mesmos procedimentos técnicos e os mesmos métodos de coleta, sistematização e análise dos dados".

Cláudio Cledson Novaes, Fernanda Aguiar C. Martins, Roberto H. Seidel (Org.) 
cada "elemento" e "aspecto", pois esta descrição mais detalhada podde ser encontrada na obra de Mieke Bal (1995). É claro que o analista não precisa, a rigor, utilizar todos os componentes da narrativa, apresentados nos próximos tópicos, cabendo a ele priorizar e eleger quais devem ser utilizados para fundamentar a sua proposta interpretativa do texto analisado.

São quatro os "elementos" da fábula a serem levados em consideração: tempo (duração e ordem), acontecimentos, atores e lugar. Relacionando-se com a adaptação fílmica de obras literárias, observamos que tais elementos geralmente estão presentes nas duas obras e são os mais passíveis de serem transferidos "equivalentemente", de uma história para outra. Contudo, por serem elementos narrativos que compõem um estrato narrativo mais superficial, podem também facilmente ser "modificados" ao passarem de uma obra para a outra (nesse caso, ficando a mercê, principalmente, das escolhas e as preferências do diretor).

Já os "aspectos"11 são: ordem, ritmo, frequência, personagem, espaço, focalização, narrador, entre outros. Todos assinalam técnicas narrativas e vão ganhando mais importância (expressividade) na formação do significado de acordo com a ordem em que estão explicitados. Devido às especificidades de cada meio, esses componentes inevitavelmente tendem a passar por negociações, operando-se, sobretudo, por meio de mudanças na forma de apresentá-los de um meio para o outro. Assim, o analista de adaptações precisa ser atento às nuances e especificidades do meio fílmico e literário, a fim de entender como os "elementos" e "aspectos" narrativos operam, causando determinados efeitos em cada meio. E, com base nisto, perceber como estes são transferidos ou "adaptados" no processo de adaptação fílmica de obras literárias.

\section{PoÉtICA do FILME E ADAPTAÇÃo CINEMATOGRÁFICA}

A metodologia Poética do Filme herda e reconfigura pelo menos dois pressupostos da poética clássica de Aristóteles. O primeiro reconhece o filme como um conjunto de dispositivos e estratégias configurado a fim de produzir efeitos específicos no espectador. Já o segundo pressuposto entende que o filme só existe como tal no ato de apreciação. O lugar da apre-

\footnotetext{
11 Para entender mais esses aspectos, pode-se aprofundar na leitura dos seguintes pesquisadores: Gérard Genette (1972), François Jost e André Gaudreault (1995) e Mieke Bal (1995).
}

154 Número temático: literatura e cinema. A Cor das Letras - UEFS, n. 11, 2010 
ciação é onde os efeitos se concretizam; identificá-lo, portanto, equivale a isolar as sensações, os sentimentos e os sentidos que se realizam no apreciador durante sua experiência. Contudo, a experiência fílmica que interessa à Poética do Filme não é exatamente a da instância empírica da apreciação.

Neste sentido, a Poética do Filme defende que a atividade do analista consiste em movimentar-se entre a apreciação e o texto do filme. Ou seja, o procedimento metodológico previsto pela Poética do Filme engloba dois estágios a serem seguidos no percurso analítico: $1^{\circ}$ ) ao interpretar um filme, o analista deve primeiro partir da apreciação e identificação dos seus programas de efeitos sobre o apreciador; e $2^{\circ}$ ) o analista deve avaliar e fazer a restituição das estratégias utilizadas para a criação destes mesmos efeitos.

Neste sentido, o investimento do analista do processo de adaptação consiste em realizar o percurso inverso ao da produção da obra, ou seja, vai-se da apreciação ao lugar onde esta foi programada. Por exemplo, a partir de emoções como comoção, angústia, medo ou riso, remontam-se as estratégias e os dispositivos (materiais e recursos) que foram capazes de gerá-las.

$\mathrm{Na}$ análise de adaptações, teríamos que incluir a esses dois percursos mais um, que seria o de observar como ocorrem as negociações das estratégias entre os programas de produção de efeitos das duas obras (filme e romance), percebendo como estas influenciam na manutenção e/ou transformação do efeito, do sentido, de uma obra para outra. A própria Poética da Adaptação parte do ato de negociar, sendo, portanto, necessário que o analista detenha-se na análise dessa negociação.

Para realizar o primeiro percurso acima sugerido, o analista deve identificar e apreciar os programas de efeitos de cada obra (filme e romance). Wilson Gomes (2004b) chama de programas a organização e a sistematização das estratégias dedicadas a buscar os efeitos que caracterizam uma obra. De acordo com os tipos de efeitos que cada obra ocasiona no fruidor, sugere que existem três programas predominantes possíveis de serem identificados em uma obra: 1) Programa Poético Sentimental ou Afetivo; 2) Programa Sensorial; e 3) Programa Cognitivo ou Comunicacional.

O Programa Poético Sentimental ou Afetivo trata da dimensão sentimental ou afetiva da obra, que pode produzir um estado de ânimo específico no apreciador, ou seja, um determinado efeito emocional, como horror, compaixão, graça e etc. Por sua vez, o Programa Sensorial refere-se basicamente a obras que configuram sua expressão com intenção de solicitar a 
subjetividade do intérprete em termos sensoriais. A obra pode provocar sensações, como calor, frio, escuridão, clareza, sinestesias, entre outros. Já o terceiro programa, que abrange os efeitos cognitivos ou comunicacionais, parte da noção de que a obra é organizada para transmitir uma mensagem, transferir ideias, ou seja, para produzir sentido.

Após a identificação do Programa, a Poética do Filme sugere que o analista avalie e restitua os efeitos, as estratégias e os meios (materiais e recursos) utilizados para configurar a obra. É, sobretudo, com a análise de certos meios - como parâmetros visuais, que incluem as dimensões cromáticas e fotográficas (incidência angular, escala de planos, nitidez, contraste, tonalidade, brilho, foco, profundidade de campo, enquadramento, movimentos de câmera, raccords), parâmetros sonoros (da música a sonoplastia) e parâmetros cênicos (direção, atuação de atores, cenários, figurinos) - e de determinados recursos e estratégias da Narratologia, apresentados anteriormente, que o analista ampliará sua compreensão do funcionamento, da organização, do programa de produção de efeitos da obra fílmica. $\mathrm{E}$, consequentemente, poderá perceber um terceiro requisito fundamental para o entendimento da poética do processo de adaptação, que é a observação de como as estratégias e os recursos da narrativa literária, como os "aspectos" e os "elementos", são negociados ao serem configurados em uma obra cinematográfica.

\section{ELEMENTOS CONTEXTUAIS NA ADAPTAÇÃO}

Além da análise dos aspectos narrativos e poéticos, que basicamente se voltam para uma análise da obra em si (análise interna), acreditamos que elementos de ordem contextual devem também ser levados em consideração no estudo das obras fílmicas e literárias envolvidas no processo de adaptação.

Inclusive, os próprios adeptos da noção de recriação, como já dissemos, sugerem em suas discussões que componentes de ordem histórica, econômica, social, cultural e ideológica precisam também ser considerados. Dudley Andrew (2000), por exemplo, argumenta que as análises de adaptações precisariam considerar tanto aspectos dos sistemas de significação e de narração quanto levar em conta o campo do discurso, da prática cultural e da história artística. Já Robert Stam (2000) afirma que aspectos culturais e históricos dos locais onde os filmes são realizados e as opções ideológicas do diretor influenciam nas mudanças efetivadas na adaptação cinematográ- 
fica de obras literárias. Umberto Eco (2007), por sua vez, discute que critérios contextuais, como convenções editoriais e exigências comerciais, não devem ser vistos como extra-artísticos.

Os aspectos contextuais que podem ajudar o analista na compreensão do processo de adaptação são: 1) as condições dos meios de produção dentro da indústria cinematográfica; 2) o contexto social; 3) o contexto político, econômico e histórico; e 4) os elementos de ordem cultural e artística, entre outros.

Dentro das condições dos meios de produção, o analista pode observar o efeito de certas personalidades-estrelas, o estilo particular do estúdio, condições econômicas, produção e distribuição, predileções do diretor, convenções de gênero, técnicas e recursos das linguagens, e troca de capital simbólico, que justifica ou demanda o uso de determinados protótipos literários na adaptação, etc. Em relação ao contexto social, político, econômico e histórico, deve-se levar em conta as lutas da sociedade, as ideologias vigentes no período, os embates políticos, a distância ou a proximidade entre os períodos em que as duas obras (filme e romance) são realizadas, entre outros. Já dentro dos elementos de ordem cultural e artística, o analista precisa observar os tipos de movimentos artísticos vigentes, os estilos, a estética, as preferências artísticas dos realizadores, as convenções de gênero e etc.

Embora todos estes aspectos possam influenciar nas negociações ocorridas no processo de adaptação, o analista não precisa usar todos, cabendo a ele determinar os que lhe convém para enriquecer sua interpretação e para contribuir no entendimento do funcionamento das obras. Além disto, é importante dizer que o analista não os deve utilizar para explicar as obras, mas sim para mostrar como são influenciadas por tais elementos. $\mathrm{Ou}$ seja, ele precisa sempre colocá-los em função do entendimento do funcionamento das obras, retornando sempre à obra em si.

\section{CONSIDERAÇÕES FINAIS}

A Perspectiva Poética de Negociação não trata e não tem o intuito de ser considerada uma teoria geral da adaptação ou de interpretação de filme e romance ou uma resposta global e precisa à pergunta sobre como analisar e discutir teórica e metodologicamente o processo de adaptação fílmica, nem muito menos é uma proposta de estudo absolutamente extraordinária ou inédita, que procura negar e criticar tudo o que tem sido feito até então. 
O desenvolvimento de tal proposta representa tanto a superação de um desafio quanto um ganho para os estudos sobre o tema adaptação fílmica. Superamos um desafio, pois mesmo com a carência de poéticas precedentes para nos ajudar a aprofundar o entendimento da questão a partir do ponto de vista que apresentamos, conseguimos desenvolver uma discussão apropriada a respeito do tema adaptação. Ganho por se tratar de outro modo de discutir o tema, que não seja o da Perspectiva Poética de Recriação ou de Fidelidade, rompendo com toda uma tradição de estudo prevalente nos trabalhos sobre a adaptação e permitindo que outras maneiras de discutir o assunto sejam incorporadas ao campo de estudos " $\mathrm{Ci}$ nema-Literatura".

\section{REFERÊNCIAS}

ANDREW, J. Dudley. Adaptation. In: NAREMORE, James. (Ed.). Film Adaptation. New Brunswick: Rutgers University, 2000, p. 28-37.

AUMONT, Jacques et al. A estética do filme. Campinas: Papirus, 2002.

BAL, Mieke. Teoría de la narrativa: Una introduccíon a la naratología. Madrid: Cátedra, 1995.

BALOGH, Ana Maria. Conjunções, disjunções, transmutações: da literatura ao cinema e à TV. São Paulo: Annablume, 1996.

BARRETO, Rodrigo. A fabricação do ídolo pop: a análise textual de videoclipes e a construção da imagem de Madonna. Dissertação (Mestrado em Comunicação). Salvador: UFBA, 2005.

BORDWELL, David. Narration in the Fiction Film. Madison, USA: The University of Wisconsin Press, 1985.

BRITO, João Batista B. Literatura, cinema, adaptação. Graphos, João Pessoa, ano I, n. 2, p. 928, 1995.

CANGUÇU, Cristiano. A construção narrativa e plástica do filme Matrix. Dissertação (Mestrado em Comunicação). Salvador: UFBA, 2008.

CARVALHO, Ludmila. A poética dos anjos caídos: um estudo sobre o cinema de Wong KarWai. Dissertação (Mestrado em Comunicação). Salvador: UFBA, 2004).

CATRYSSE, Patrick; BRUSSEL, K. U. Film (Adaptation) as Translation: Some Methodological Proposals. Amsterdam/Philadelphia: John Benjamin's Publishing Company, 1992.

ECO, Umberto. Obra aberta: forma e indeterminação nas poéticas contemporâneas. São Paulo: Perspectiva, 1971.

ECO, Umberto. Lector in fabula. São Paulo: Perspectiva, 1986.

ECO, Umberto. Os limites da interpretação. São Paulo: Perspectiva, 1995.

ECO, Umberto. Quase a mesma coisa. Rio de Janeiro: Record, 2007.

GENETTE, Gérard. Discurso da narrativa. Lisboa: Vega Universidade, 1972. 
GOMES, Wilson. Metáforas da diferença: a questão do inteiramente outro a partir da teoria da construção. Trans/Form/Ação: Revista de Filosofia, São Paulo: UNESP, v. 15, p. 131-148, 1992.

GOMES, Wilson. As estratégias de produção de encanto. O alcance contemporâneo da poética de Aristóteles. Textos de Cultura e Comunicação, Bahia, v. 35, p. 99-125, jun. 1996.

GOMES, Wilson. La poética del cine y la cuestión del metodo en el análisis fílmico. Significação, Curitiba, v. 21, n. 1, p. 85-106, 2004a.

GOMES, Wilson. Princípios de Poética (com ênfase na poética do cinema). In: PEREIRA, M.; GOMES, R.; FIGUEIREDO, V. (Org.). Comunicação, representação e práticas sociais. Rio de Janeiro, 2004b, p. 93-125.

JOHNSON, Randal. Literatura e cinema, diálogo e recriação: o caso de vidas secas. In: PELLEGRINE, Tânia. (Org.). Literatura, cinema e televisão. São Paulo: Editora Senac, 2003, p. 37-59.

JOST, François; GAUDREAULT, André. El relato cinematográfico: Cine y narratología. Barcelona: Ediciones Paidós Ibérica, 1995.

MAIA, Guilherme. Elementos para uma poética da música do cinema: ferramentas conceituais e metodológicas aplicadas na análise da música dos filmes "Ajuste final" e "O homem que não estava lá". Tese (Doutorado em Comunicação). Salvador: UFBA, 2007.

MCFARLANE, Brian. Novel to Film: An Introduction to the Theory of Adaptation. New York: Oxford University Press, 1996.

NAREMORE, James. (Ed.). Film Adaptation. New Brunswick: Rutgers University, 2000.

OLIVEIRA, Marinyze Prates de. Olhares roubados: cinema, literatura e nacionalidade. Salvador: Quarteto, 2004.

PEÑA-ARDID, Carmen. Literatura y cine: Una aproximación comparativa. Madrid: Ediciones Cátedra, 1992.

RAY, Robert B. The Field of "Literature and Film". In: NAREMORE, James. (Ed.). Film Adaptation. New Brunswick: Rutgers University, 2000, p. 38-53.

SOUSA, Sérgio Paulo Guimarães de. La belle infidéle: adaptação e fidelidade. In: Congresso Internacional da Associação Portuguesa de Literatura Comparada. Universidade de Évora, 9 Mai, 2001, Portugal. Artigo. Portugal, 2001. p. 1-15. Disponível em: http://www.eventos. uevora.pt/comparada/VolumellI/LA\%20BELLE\%20INFIDELE.pdf. Acesso em: 23 jul. 2007.

STAM, Robert. Beyond Fidelity: The Dialogics of Adaptation. In: NAREMORE, James. (Ed.). Film Adaptation. New Brunswick: Rutgers University, 2000, p. 54-76.

STAM, Robert. A literatura através do cinema: realismo, e a arte da adaptação. Belo Horizonte: Editora UFMG, 2008.

VANOYE, Francis; GOLIOT-LÉTÉ, Anne. Ensaio sobre a análise fílmica. Campinas: Papirus, 1994.

VERNET, Marc. Cinema e narração. In: AUMONT, Jacques et al. A estética do filme. Campinas: Papirus, 2002, p. 89-156.

VIRGINIA, Jorge. Coração de ouro: o cinema melodramático de Lars Von Trier. Dissertação (Mestrado em Comunicação). Salvador: UFBA, 2006. 
WHELEHAN, Imelda; CARTMELL, Deborah. Adaptations from Text to Screen, Screen to Text. New York: Routledgde, 1999. 